Review Article

\title{
Investigating the Value of Abatacept in the Treatment of Rheumatoid Arthritis: A Systematic Review of Cost-Effectiveness Studies
}

\author{
Kostas Athanasakis, Ioannis Petrakis, and John Kyriopoulos \\ Department of Health Economics, National School of Public Health, 196 Alexandras Avenue, 11521 Athens, Greece \\ Correspondence should be addressed to Kostas Athanasakis; kathanasakis@esdy.edu.gr
}

Received 24 March 2013; Accepted 29 April 2013

Academic Editors: J. Anguita, J. L. Pérez-Castrillon, and S. Verstappen

Copyright (C) 2013 Kostas Athanasakis et al. This is an open access article distributed under the Creative Commons Attribution License, which permits unrestricted use, distribution, and reproduction in any medium, provided the original work is properly cited.

\begin{abstract}
Background. Rheumatoid arthritis is a progressive inflammatory disease that affects greatly patients' quality of life and demands for aggressive management early on during the course of the disease. The discovery of biologics has equipped rheumatologists with evolutionary treatment tools but has also impacted greatly management costs. Objectives. To conduct a systematic review in order to evaluate the cost effectiveness of abatacept in the treatment of moderate to severe rheumatoid arthritis. Methods. Pubmed, the International Society for Pharmacoeconomics and Outcomes Research Outcomes Research Digest, the National Health System Economic Evaluation Database, and the Database of Abstracts of Reviews of Effects were searched. Results. In total 301 studies were identified and 42 met the inclusion criteria. Half of the selected studies evaluated abatacept in the treatment of rheumatoid arthritis, after failure of or intolerance to tumor necrosis factor alpha inhibitors. Of those, $82 \%$ were in favor of abatacept as a cost-effective or dominant strategy versus varying alternatives, whereas $18 \%$ favored other treatments. Conclusion. The majority of evidence from the published literature supports that abatacept can be a cost-effective alternative in the treatment of moderate to severe rheumatoid arthritis, especially in patients that have demonstrated inadequate response or intolerance to anti-TNF agents or conventional disease modifying antirheumatic drugs.
\end{abstract}

\section{Introduction}

Rheumatoid arthritis (RA) is a systemic inflammatory disease that presents itself in multiple joints of the musculoskeletal system. Symptoms include joint swelling, redness, and pain with gradual joint deformity in some cases. Due to its pathophysiology, RA causes not only significant morbidity and progressive loss of quality of life, but also carries a substantial economic burden, both for the individuals as well as for the society as a whole, since it is associated with high intense short- and long-term healthcare resource utilizations due to its increased prevalence and disability potential [1].

Over the last two decades, researchers have equipped rheumatologists with revolutionary therapeutic options. However, these changes have not been fully brought into effect in many European countries and other parts of the world $[2,3]$. Disease-modifying antirheumatic drugs (DMARDs) represent the mainstay of RA management. Corticosteroids and nonsteroidal anti-inflammatory drugs (NSAIDs) are also employed, mainly in the short-term, arthritis-related, symptomatic mitigation. Recently, several disease modifying biologic agents have been licensed for the management of RA, alone or in combination with methotrexate (MTX). These agents include abatacept (ABA), adalimumab (ADA), anakinra (ANA), certolizumab pegol (CER), etanercept (ETA), golimumab (GOL), infliximab (INF), rituximab (RTX), and tocilizumab (TOC).

Abatacept is a selective modulator that blocks T-cell activation. It has a marketing authorisation for use in combination with MTX for the treatment of moderate to severe active rheumatoid arthritis in adults whose disease has responded inadequately to previous therapy with one or more DMARDs, including MTX or a tumour necrosis factor (TNF) inhibitor [4]. Its unique mode of action results in inhibition of the inflammatory cascade by preventing activation of T-cells through binding to the natural ligands CD80 and CD86 not 
allowing their interaction with CD28 on the T-lymphocyte [5].

The plethora of therapeutic options available and the variability of patient subgroups that represent target populations for each medication have led to the publication of a number of guidelines and treatment algorithms internationally. Among the agencies that have published such guidance, the National Institute of Clinical Excellence (NICE) has issued several guidelines on the use of biologics in RA [6], producing a rather complex prescribing regime [7]. According to the NICE recommendations, TNF antagonists are the only class of biologic agents that can be used as first line therapy, limiting the use of other agents with different mode of action. Biologic DMARD sequencing cannot be pinpointed accurately after intolerance to or failure of a TNF antagonist, and thus treatment regimens should be based not only to the licensed indications, but to the cost-effectiveness data available [6]. The latter has become a global objective, especially today, since scarcity of resources is more than evident.

In light of the aforementioned, the purpose of the present study was to conduct a systematic review of cost-effectiveness studies of abatacept in order to evaluate the role of this agent in the treatment of moderate to severe rheumatoid arthritis, specializing to treatment algorithms after previous inadequate response or intolerance to disease modifying antirheumatic drugs (DMARDs) and/or TNF inhibitors.

\section{Materials and Methods}

2.1. Overview. The literature search was extended to a wide range of databases, in order to include as much and as recent information as possible. The databases that were searched included Pubmed, the International Society for Pharmacoeconomics and Outcomes Research (ISPOR) Outcomes Research Digest, the National Health System Economic Evaluation Database (NHS EED), and the Database of Abstracts of Reviews of Effects (DARE). Overlapping hits were included once. The literature search was not limited by study type or publication year; however, study selection was limited to articles written in English (inclusion and exclusion criteria are listed in detail later). For economic evaluation data, the outcomes included cost effectiveness and related types of analyses (including cost consequence, cost of treatment, and budget impact studies).

2.2. Preliminary Search. A preliminary database search was conducted in order to challenge the systematic review strategy, focusing on the keywords to be used and the need for limiting the main literature search. Furthermore, it provided an estimate of the size of the literature available on the specific topic.

2.3. Main Search. The main search was carried out in August 2012. Slightly different strategies were employed for each database searched due to inherent limitations pertaining to the type and classification of information. An initial search using the keywords "abatacept, cost effectiveness, and rheumatoid arthritis" was carried out in Pubmed. The
Pubmed search was enriched by selecting the "related citations" option to each one of the initial results. The study that was selected as the basis for related citations was one containing all keywords in the title and was deemed the most relevant to the objective [8]. The ISPOR Outcomes Research Digest was searched by using the in-title term "abatacept" in the "rheumatoid arthritis" disease/disorder section. Additional searches employed the same strategy; however, the disease/disorder section selected was "arthritis" and "Muscular-skeletal Disorders (including Tunnel Syndrome)." No other limits were used. DARE and NHS EED databases were searched through the Centre for Reviews and Dissemination. "Abatacept" and "rheumatoid arthritis" were searched as keywords to the titles of published studies, without limiting databases or record types.

2.4. Study Selection. Two members of the review team assessed the titles of the identified results independently. All relevant hits were then cross-checked against the inclusion and exclusion criteria. Studies that were identified by only one of the reviewers were examined in a separate meeting, in order for an inclusion decision to be reached.

2.5. Inclusion Criteria. The criteria which all initial results were examined against are listed as follows:

(i) studies comparing abatacept to other biologics or conventional therapies in rheumatoid arthritis;

(ii) studies included both systematic reviews as well as stand-alone economic evaluation studies;

(iii) types of costs included direct and indirect costseffectiveness measures included all life expectancy and quality of life outcome measures;

(iv) studies focusing on adult patients.

2.6. Exclusion Criteria. Exclusion criteria were as follows:

(i) studies comparing abatacept to other treatments in different indications than rheumatoid arthritis;

(ii) studies not reporting cost data-comparisons to other treatment options only on clinical effectiveness grounds were excluded;

(iii) studies not specifying a time horizon for costs or results (for standalone economic evaluation studies);

(iv) studies comparing treatments in juvenile rheumatoid arthritis;

(v) studies with no research abstract and/or author details available;

(vi) articles commenting on previous research studies;

(vii) studies that did not meet the quality assessment criteria.

2.7. Data Extraction and Quality Assessment. All relevant study information was extracted into predesigned tables. Fields included study information and origin, study type, type of economic evaluation, comparing treatments, results, and comments. Studies that were identified in multiple databases 
were reported once. The quality of independent economic evaluation studies was evaluated in accordance to the Centre for Reviews and Dissemination set of guidelines [9].

2.8. Analysis of Findings. All relevant studies are presented and analyzed according to the line of therapy or treatment algorithm in rheumatoid arthritis. The main analyses focused on (a) abatacept use after failure of traditional DMARD therapies and (b) abatacept use after an inadequate response (IR) to TNF-a inhibitor therapy. All other relevant pharmacoeconomic studies which met the inclusion criteria but could not be accurately classified in one of the previous approaches are presented and analyzed in a separate section (c).

\section{Results}

In total, 301 studies were identified. The initial Pubmed search produced 19 hits and the secondary search produced another 197 results. The CRD database produced 8 hits and finally the ISPOR database revealed 50, 24, and 3 matches for "rheumatoid arthritis," "arthritis," and "Muscular-skeletal Disorders (including Tunnel Syndrome)" disease sections, respectively. After the inclusion and exclusion criteria were applied, 42 studies were finally selected. The majority of rejected studies were due to lack of cost data, failure to include abatacept as a comparator to other biologic agents, and failure to include RA as a treatment indication. Other reasons for exclusion included failure to meet the quality assessment criteria (1 study) and comparison of different biologic sequences, where results were presented for single agents (other than abatacept) and not the entire sequencing strategy containing abatacept (2 studies).

3.1. Abatacept after Conventional DMARD. In total 9 studies on the cost effectiveness of abatacept in the treatment of rheumatoid arthritis after failure of or intolerance to conventional DMARDs were identified. All retrieved publications followed the cost-effectiveness analysis. Two of the previous also presented budget impact data for the agents under comparison. The results are presented in detail in Table 1.

3.2. Abatacept after TNF-Antagonist. In total 21 studies on the cost effectiveness of abatacept in the treatment of rheumatoid arthritis after failure of or intolerance to TNF-a inhibitors were identified. Apart from the "classic" economic evaluations in the form of cost-effectiveness analysis, the results under this section included other approaches, such as cost of therapy and budget impact analysis. The results are presented in detail in Table 2.

3.3. Other Pharmacoeconomic Studies Involving Abatacept. An additional 12 pharmacoeconomic studies relevant to the role of abatacept in the treatment of rheumatoid arthritis were identified but could not be included into one of the two major treatment pathways mentioned earlier. Those studies mainly included abatacept use after conventional DMARD therapy and anti-TNF replacement or studies that failed to specify the line or sequence of treatment and simply compared the cost effectiveness of abatacept against other modes of therapy. Those results are presented in Table 3.

3.4. Summary of Findings. A wide range of economic evaluation and cost-analysis studies were identified with several comparators under investigation. Abatacept mainly appears to have been studied after failure of a TNF inhibitor. In regards to the economic evaluation studies, abatacept's cost effectiveness appears to range within the acceptable costeffectiveness thresholds according to the authors in the majority of studies. In general, abatacept versus comparators after conventional DMARDS appear to have a higher cost effect ratio when compared to abatacept versus comparators after TNF failure. Other cost analyses are highly dependent on the country of origin and the comparator treatments used.

\section{Discussion}

The disease and economic burden of RA remains substantial for the patients and health systems of developed economies worldwide. The continuously increasing therapeutic armamentarium provides clinicians with numerous options for the treatment of RA. Even when adopting the health economics point of view, it is safe to emphasize on the need for mutual patient-clinician agreement on the treatment options and strategy to be followed throughout the course of the disease, as recommended by an international task force on RA [3]. However, the context of "scarce resources versus infinite needs" in which health systems are obliged to operate nowadays (more than ever) necessitates that all options should be evaluated both in terms of their cost as well as in terms of their effectiveness, in order to rationalize the allocation of resources and achieve economic efficiency, that is, more and better "health" for the given resources.

Placed in the previous line of thought, the present study aimed to review the existing economic evaluation evidence for abatacept, a recently approved agent for the treatment of RA [9]. For that purpose, a systematic literature review was performed in order to depict a thorough overview of the clinicoeconomic value of abatacept in the management of rheumatoid arthritis, compared to existing alternatives.

4.1. Cost Effectiveness of the Use of Abatacept following Conventional DMARDs. The criteria to initiate a biologic agent after failure of conventional DMARDs have been analyzed by several rheumatology bodies (ACR, EULAR, BSR) [6]. Usually, a biologic is started after failure to achieve a DAS28 of $<3.2$ with conventional therapies [51]. The results of the systematic review on the use of abatacept after failure of DMARDs included studies mostly performed in American countries and in lesser cases in the European setting, evaluating the use of abatacept or other agents, after failure of methotrexate and taking into account a third party payer (social insurance) perspective.

In all 9 studies that were retrieved, abatacept was a cost-effective strategy against comparators after failure of methotrexate, although in varying degrees. This ranged from 


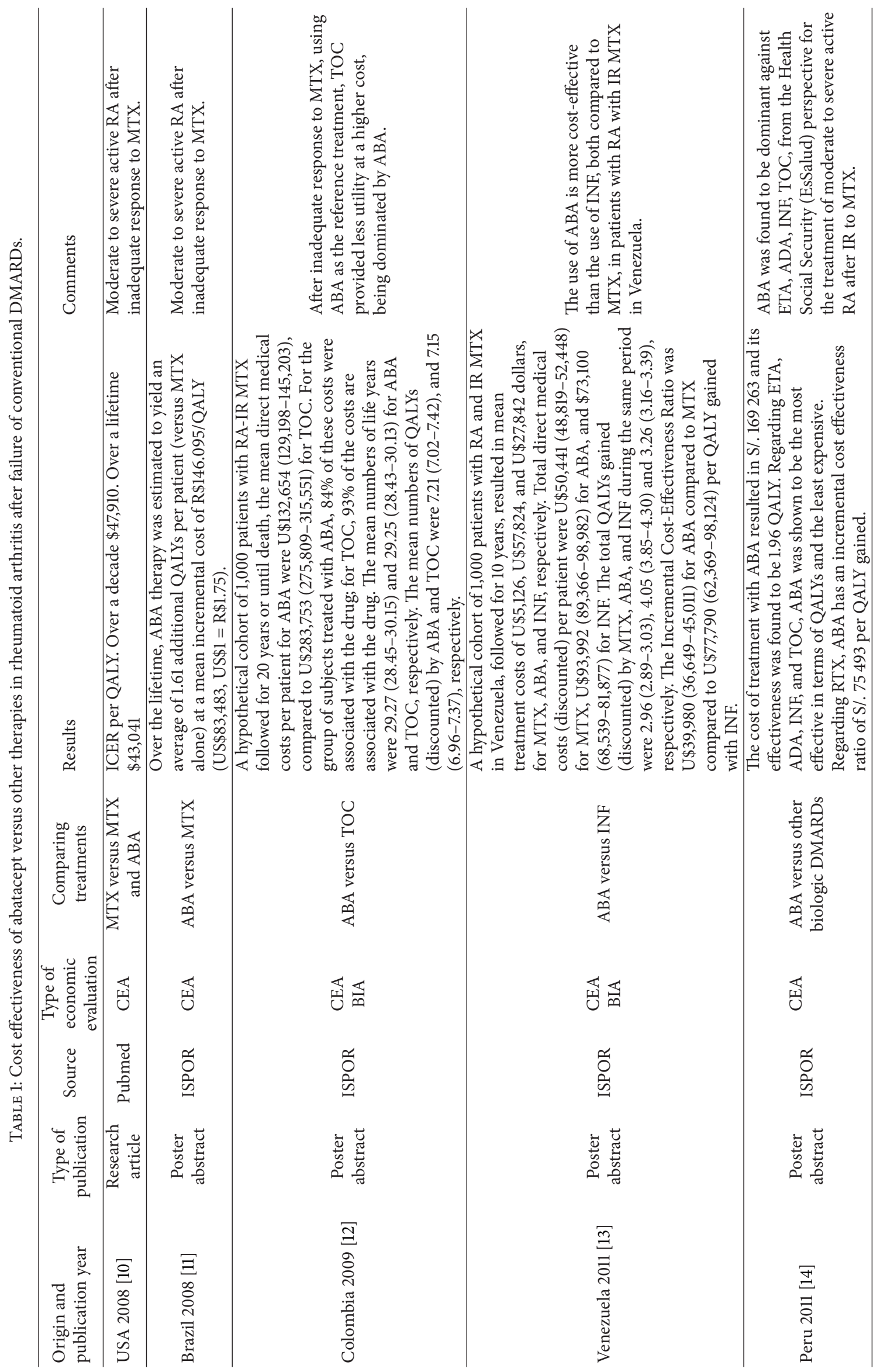




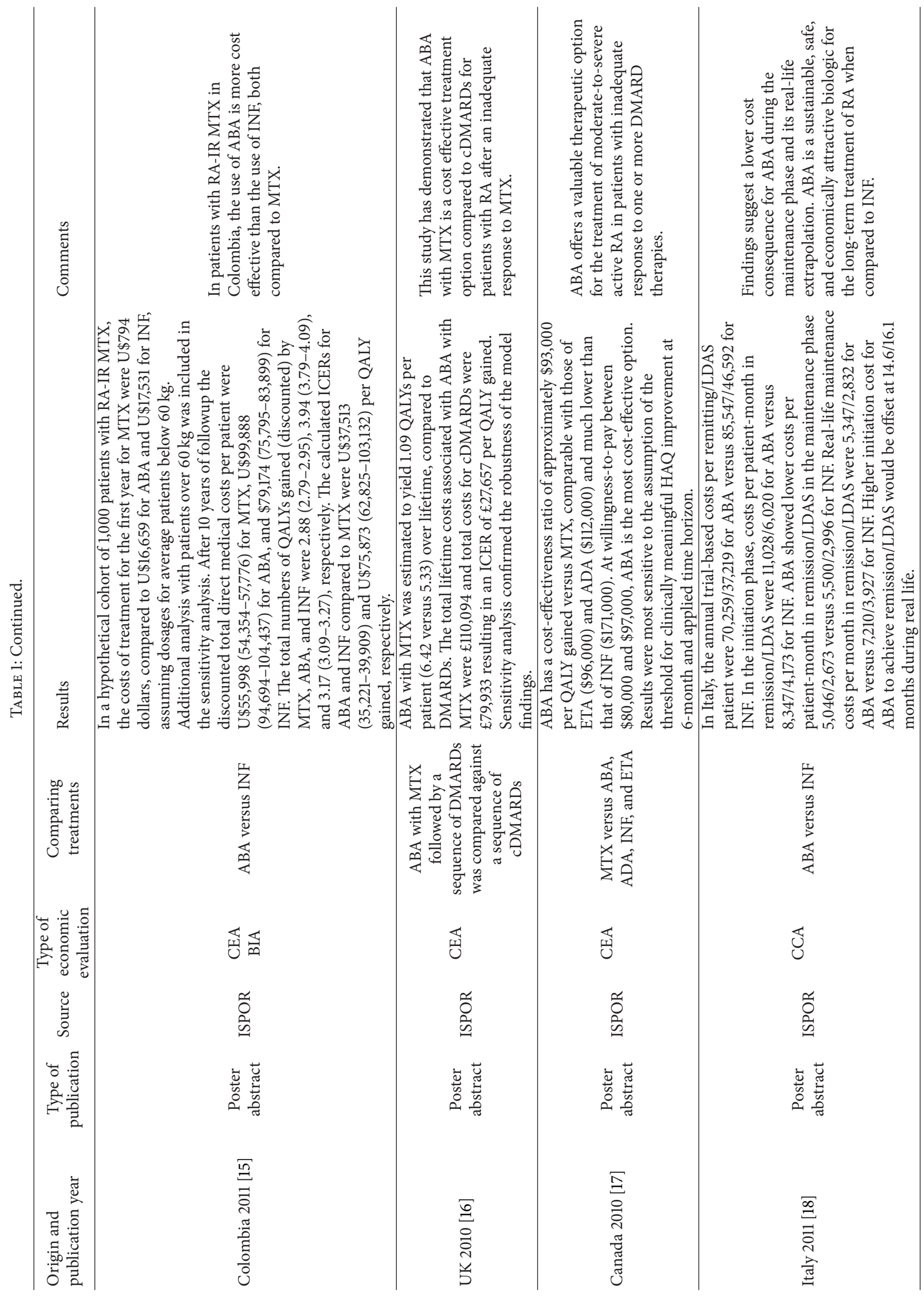




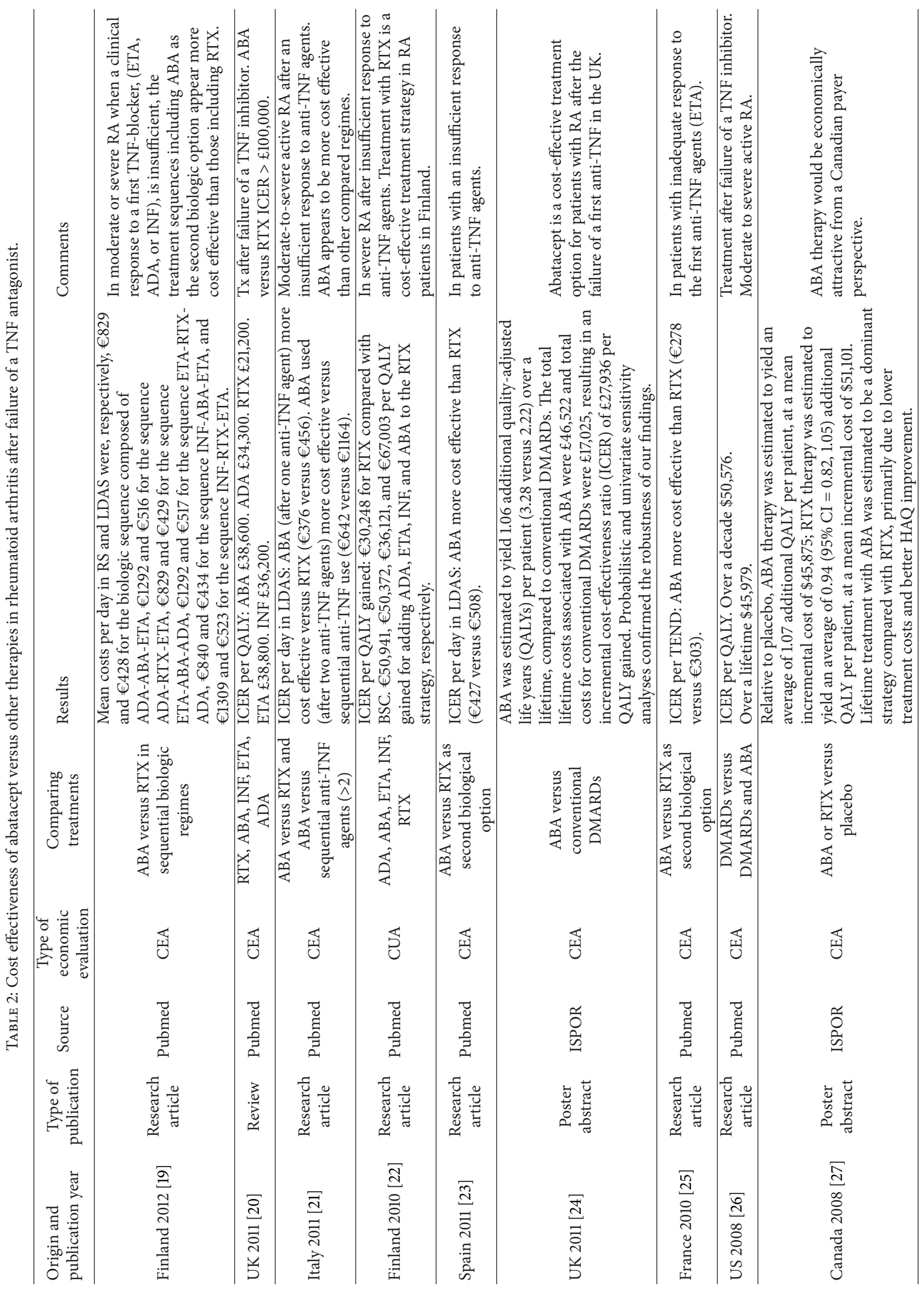




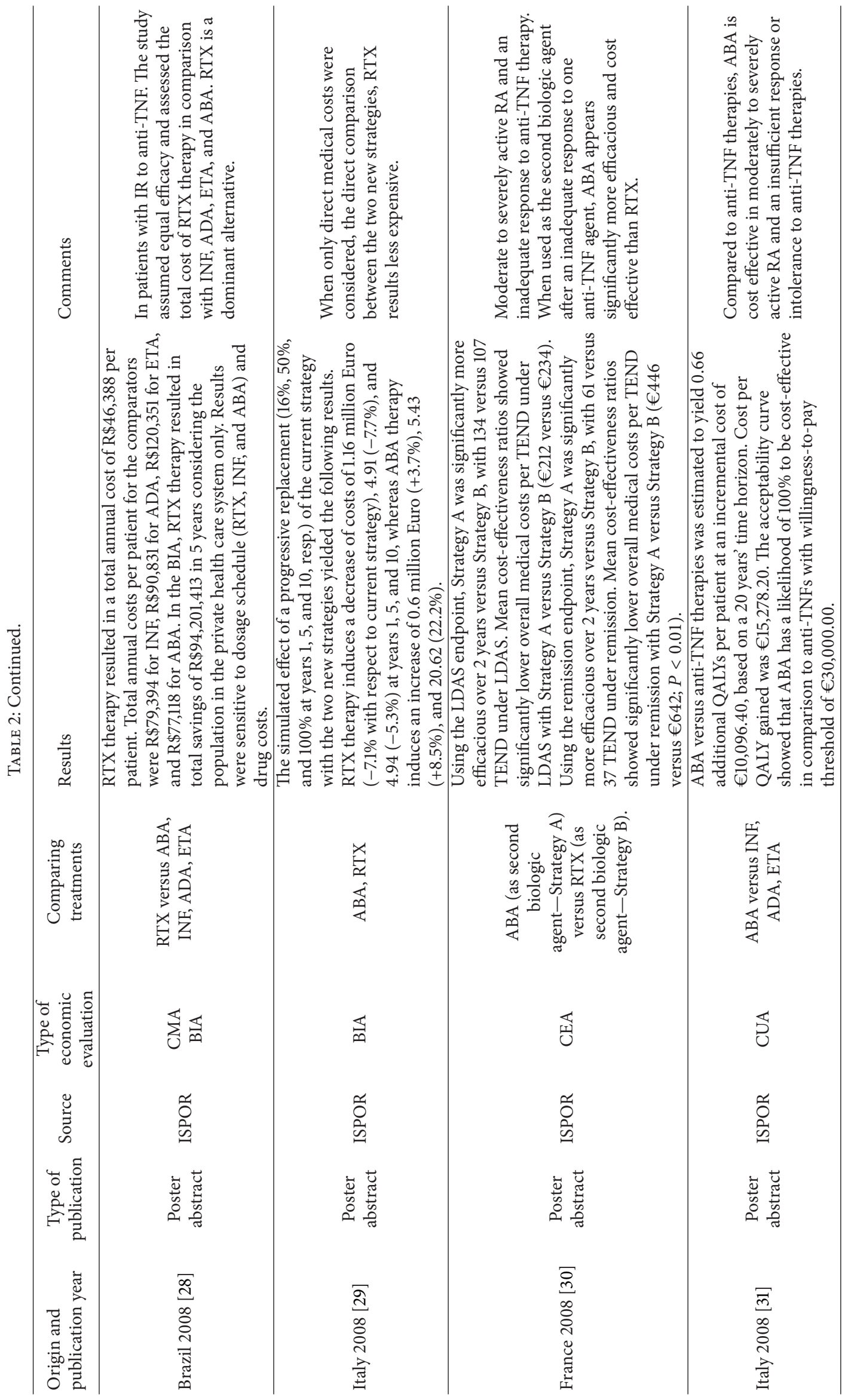




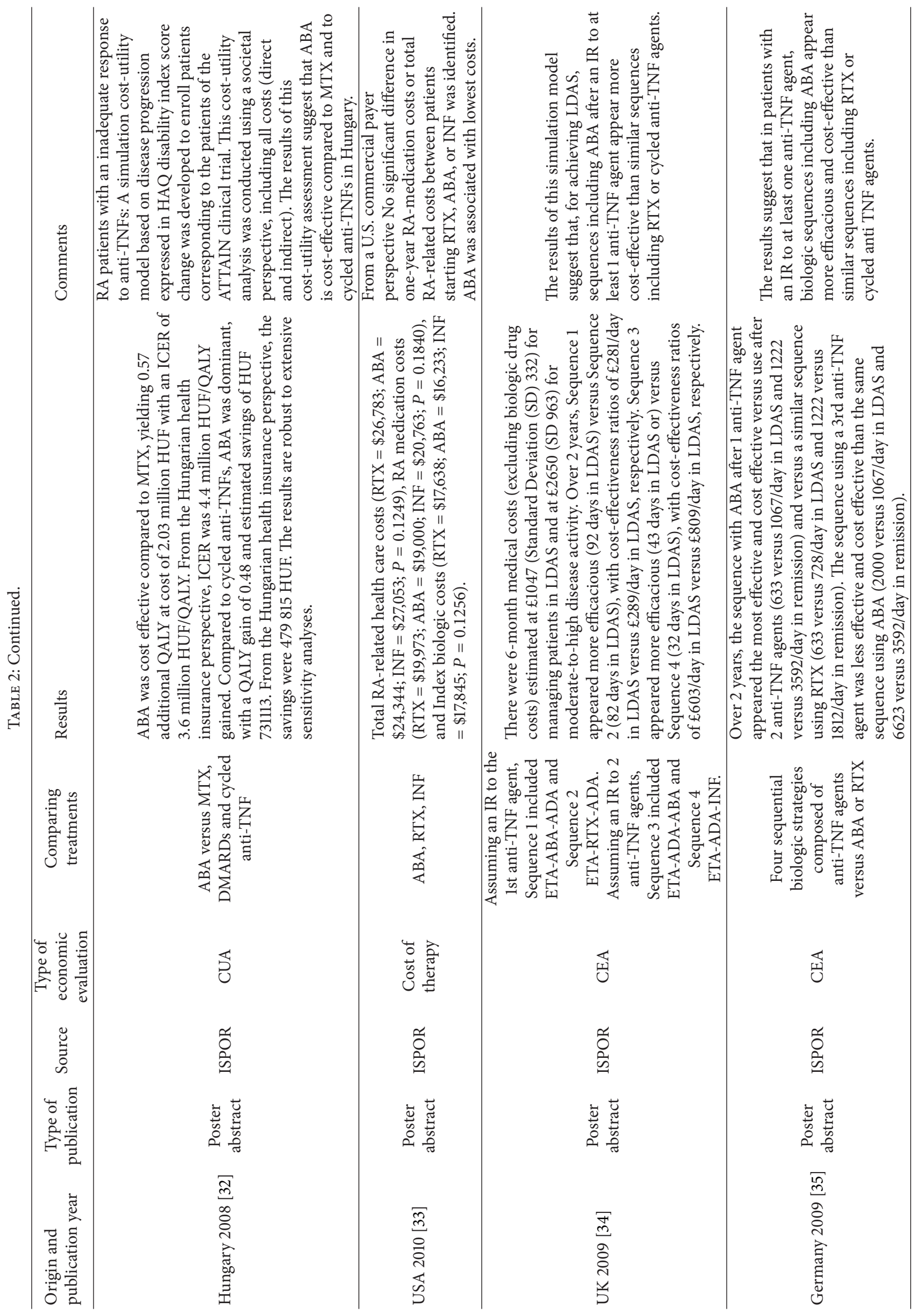




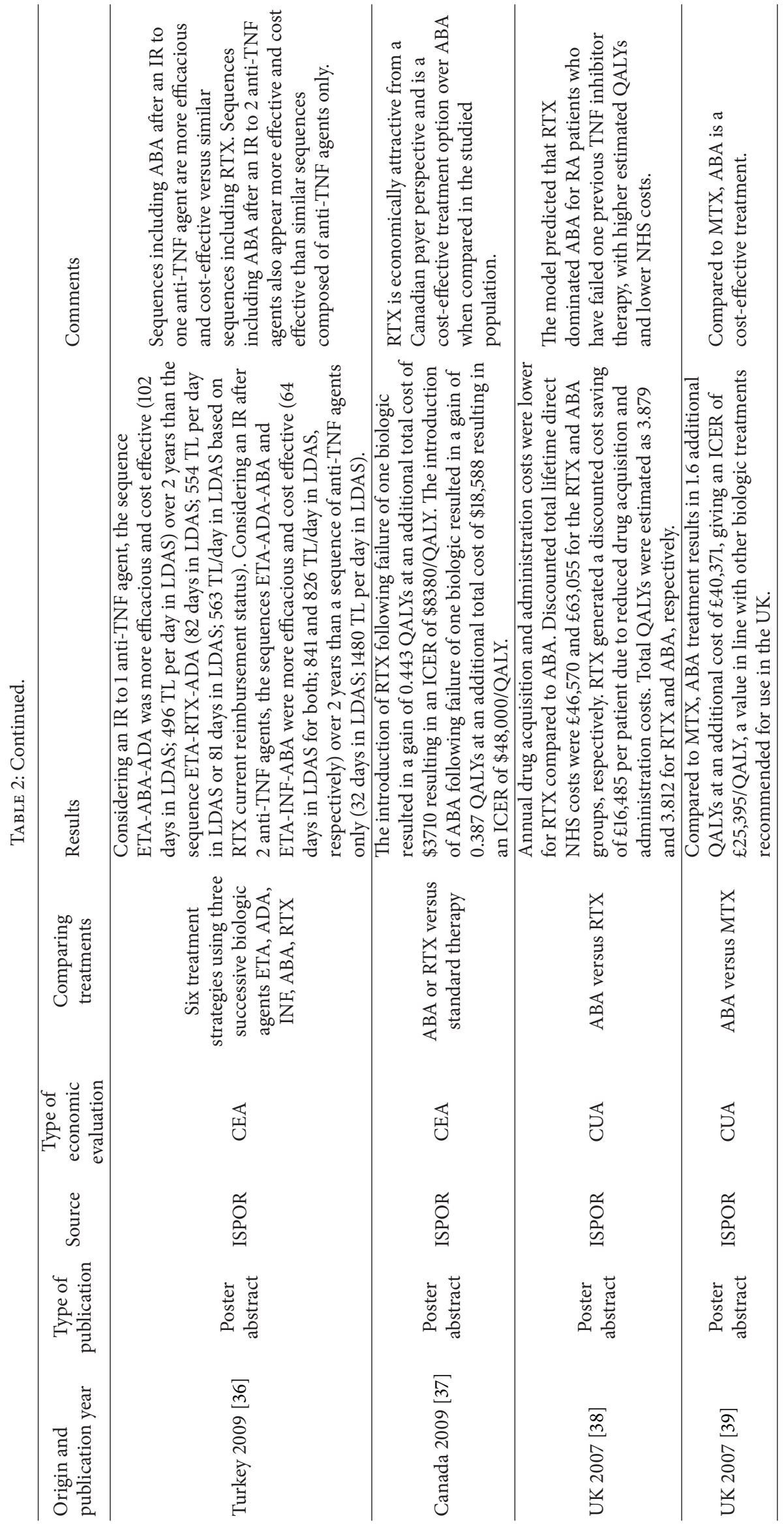




\begin{tabular}{|c|c|c|c|c|c|c|c|}
\hline $\begin{array}{l}\text { 节 } \\
\text { : } \\
0 \\
0\end{array}$ & 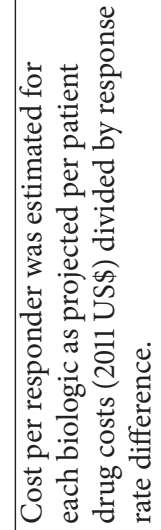 & 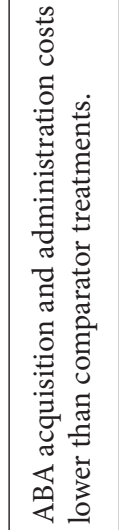 & 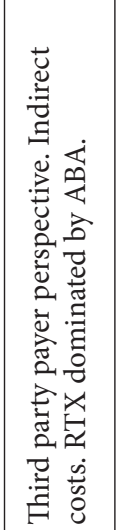 & 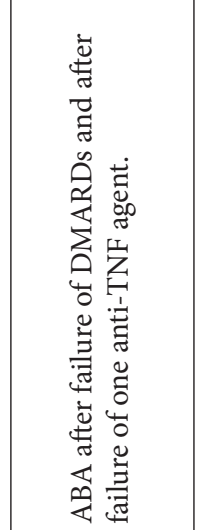 & 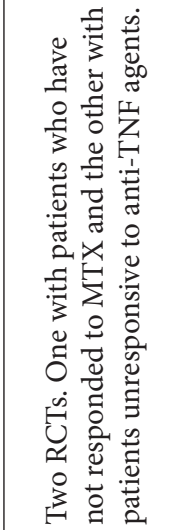 & 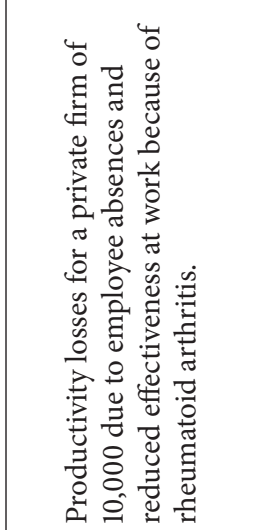 & 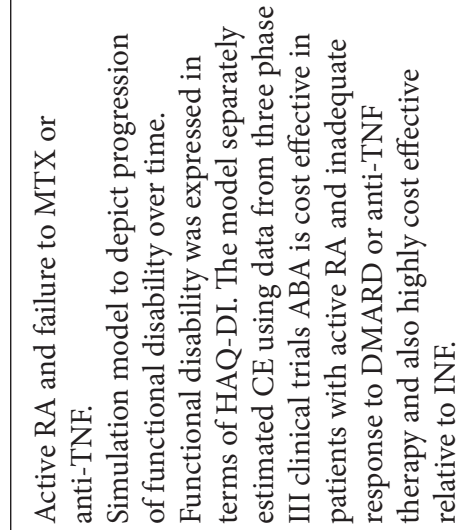 \\
\hline 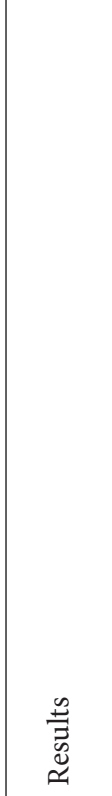 & 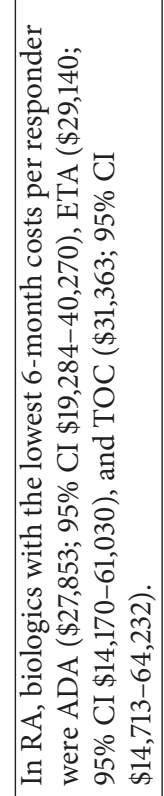 & 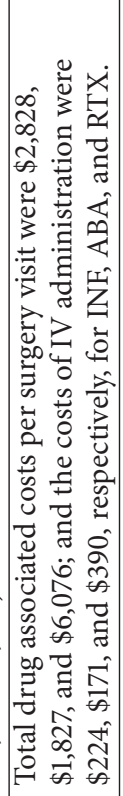 & 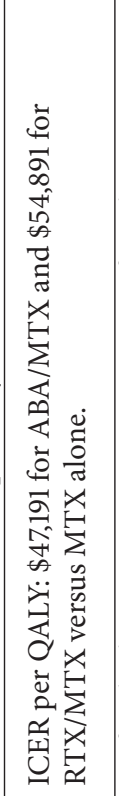 & 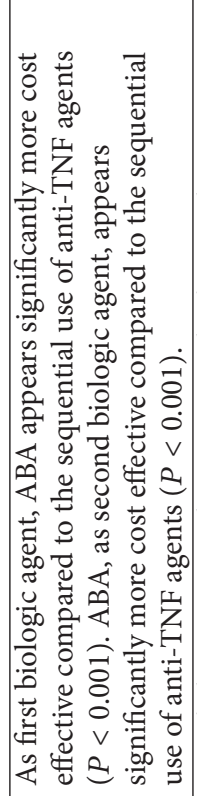 & 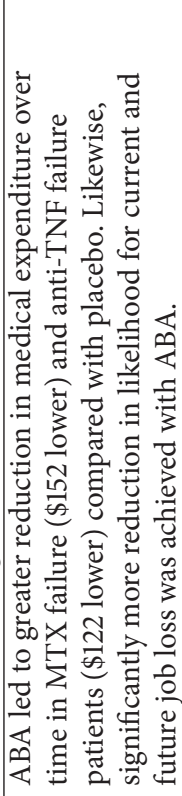 & 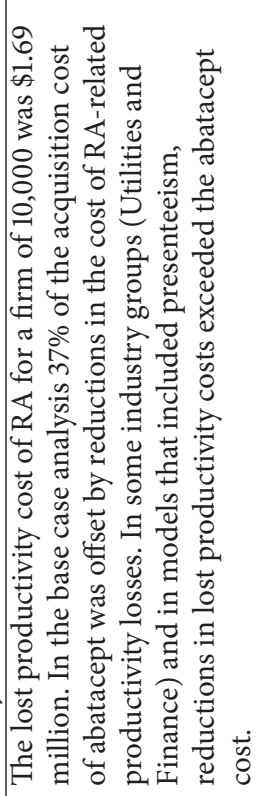 & 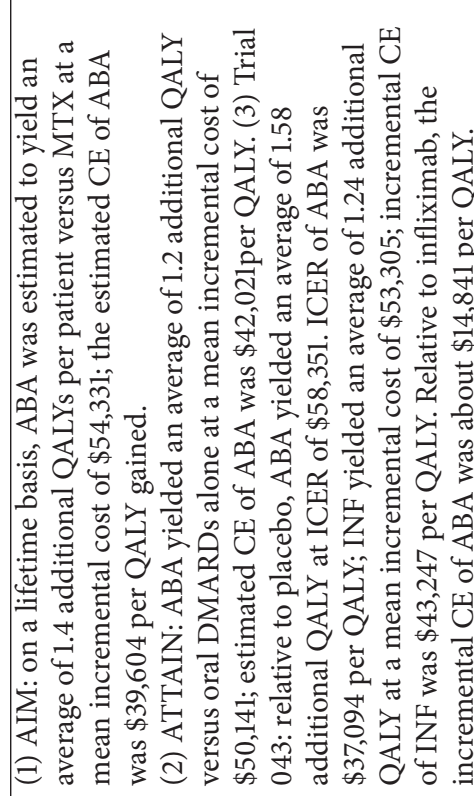 \\
\hline 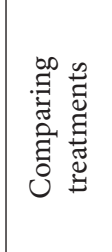 & 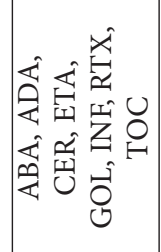 & 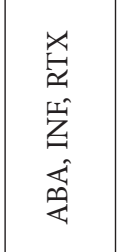 & 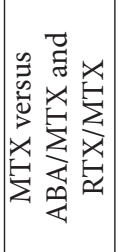 & 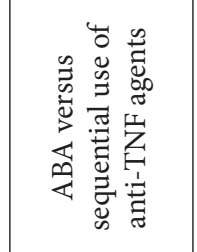 & 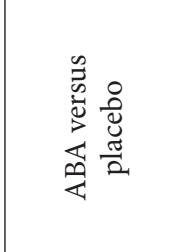 & 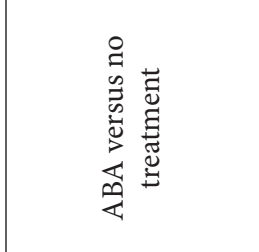 & 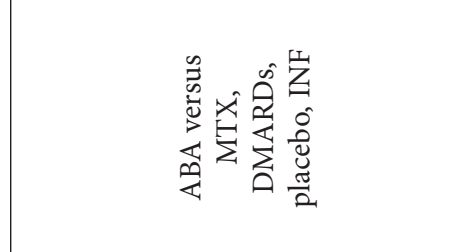 \\
\hline 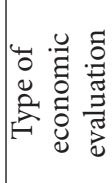 & 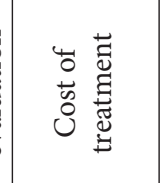 & 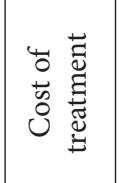 & 岂 & 嵌 & 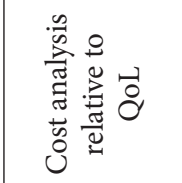 & 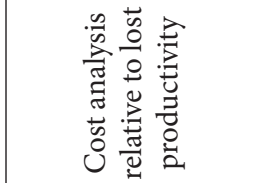 & 秥 \\
\hline $\begin{array}{l}\tilde{\Xi} \\
\stackrel{\Xi}{0} \\
\dot{s}\end{array}$ & 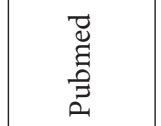 & $\begin{array}{l}\vec{\Xi} \\
\tilde{\Xi} \\
\vec{\Xi} \\
\vec{\Xi}\end{array}$ & 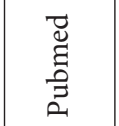 & $\begin{array}{l}\vec{\Xi} \\
\ddot{\Xi} \\
\vec{\Xi}\end{array}$ & 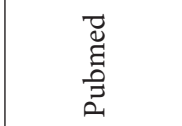 & $\begin{array}{l}\vec{\Xi} \\
\vec{\Xi} \\
\vec{\Xi}\end{array}$ & 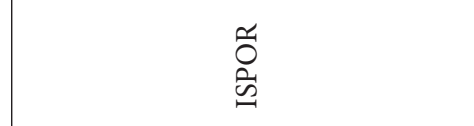 \\
\hline 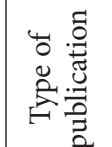 & 憂 & 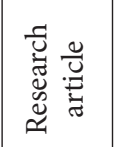 & 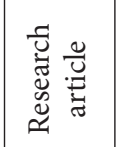 & 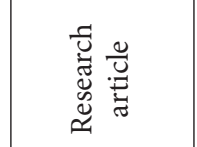 & 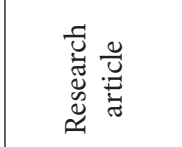 & 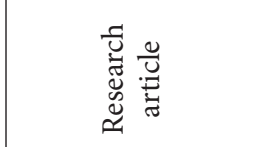 & 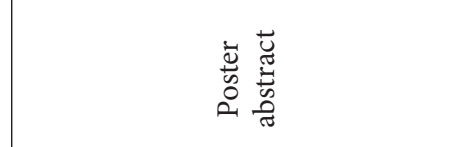 \\
\hline 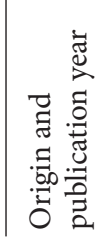 & a & $\begin{array}{l}\bar{\Xi} \\
\vdots \\
\bar{b}\end{array}$ & 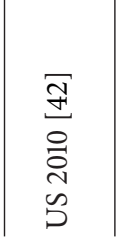 & 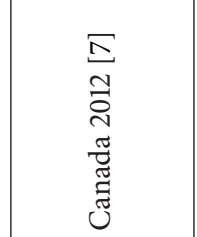 & 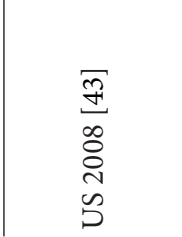 & 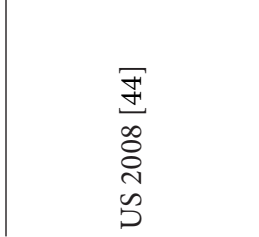 & 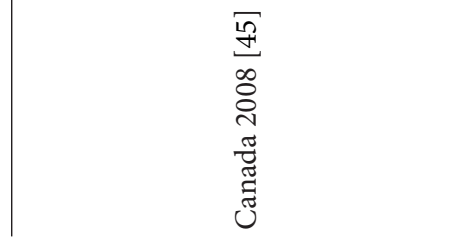 \\
\hline
\end{tabular}




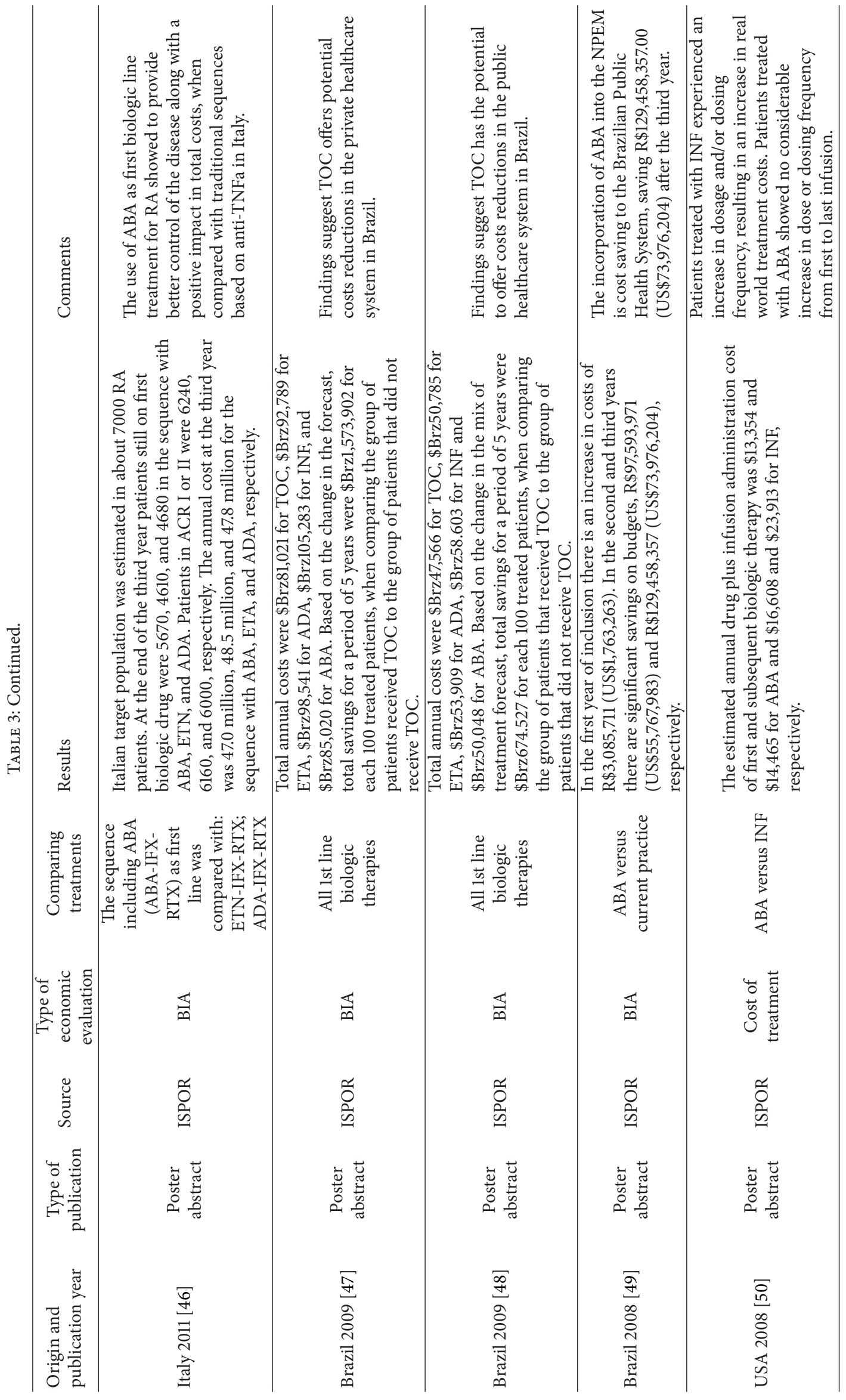


abatacept being a dominant strategy (i.e., more effective and less costly), versus etanercept, adalimumab, infliximab, and tocilizumab ([14], for the health system of Peru) and tocilizumab alone ([15], for the health system of Colombia), to borderline cost effective, the latter depending on the acceptability threshold that is used for local reimbursement decisions.

In some cases of the referenced studies, abatacept led to reductions in the total costs of treatment accompanied (in all cases) by gains in Quality Adjusted Life Expectancy, thus leading to favorable economic evaluation results.

Specifically, when compared to infliximab, abatacept proved to be associated with higher treatment costs, especially during the initiation phase $[12,14,16,17]$. However, all of the previous studies concluded on the cost effectiveness of abatacept compared to infliximab, as these costs were offset by the increased number of QALYs gained. One study [17] estimated the offsetting of costs to take place at a maximum of around 16 months after initiation, claiming that abatacept appears to be an economically attractive, long-term treatment option in RA. Another study comparing the combination of abatacept and methotrexate with conventional DMARD treatment after failure of methotrexate alone also demonstrated that the abatacept strategy was able to offset the higher treatment costs, producing an ICER per QALY gained of $£ 27,657$. The indirect comparison to other biologic therapies, such as etanercept and adalimumab $[13,16]$, demonstrated the cost effectiveness of abatacept in active rheumatoid arthritis after inadequate response to conventional DMARDs. One study compared rituximab with abatacept [13]. Regarding RTX, ABA has an incremental cost-effectiveness ratio of S/75 493 per QALY gained.

4.2. Cost Effectiveness of the Use of Abatacept following TNF-a Inhibitors. The majority of retrieved results investigated the cost effectiveness of abatacept use after inadequate response or intolerance to one or more TNF-a antagonists $(N=21)$. Most studies focus on the comparison between abatacept and rituximab, either "head to head" or with the inclusion of other alternatives. This comparison is in favor of abatacept, since 10 studies report that abatacept is more cost effective or dominant versus rituximab and 4 state the opposite. However, it needs to be noted that 2 of the 4 studies in favor of rituximab are based on the (rather bold) hypothesis of equal efficacy across all agents under evaluation, thus selecting the cheapest one as the dominant option ([28] for the Brazilian healthcare setting and [29] for the Italian health care setting).

Other findings of interest include the improved cost effectiveness of abatacept compared to methotrexate in Hungary [31] and the UK [38], the association of abatacept with lower overall costs of treatment from a managed care perspective in the US [32], and the favorable cost-effectiveness results of abatacept in comparison to DMARDs in general $[23,25]$.

4.3. Abatacept and Its Value as Presented in Other Types of Pharmacoeconomic Analyses. A series of other economic evaluations of abatacept could not be classified to the previously mentioned major treatment pathways. Nevertheless, they provide some useful insights of the value of abatacept in the treatment of RA patients. Indicatively (a) the cost utility analysis by Wong et al. [41] (comparing methotrexate and abatacept regimens versus methotrexate and rituximab or methotrexate alone), which demonstrated that the combination of methotrexate and abatacept was well within the US cost-effectiveness threshold and (b) the analysis of abatacept versus sequential use of anti-TNF agents for the Canadian health care setting [7] which demonstrated that abatacept was highly cost effective.

Regarding the macroeconomics of the healthcare system, cost-of-illness analyses can be of great use to decision makers. In this field, Wong et al. have demonstrated lower acquisition and administration costs for abatacept [41] although a recent review [40] did not include the agent among those with the lowest cost per responder. Of particular interest is the study of Cole et al. [43] who showed that the use of abatacept can fully offset productivity losses for RA patients, a finding similar to that by Yuan et al. [42].

4.4. Limitations. Being performed in an environment with inherent uncertainty, economic evaluations of health interventions, especially in the rheumatoid arthritis, are characterized by a number of limitations points of discussion that should be addressed when interpreting the outcomes of any analysis. A limitation that applies for most of the economic evaluations presented here lies in the fact that the majority of them adopts a third party payer perspective, thus including only those costs that are relevant for a social security organization and not incorporating the so called "societal costs." Third party payer perspective analyses are really useful when pricing or, especially, when reimbursement decisions must be supported; this is why they are currently acceptable according to most national and international guidelines for economic evaluations and performed more often than evaluations with a societal perspective. However, this way entails exclusion of a large fraction of indirect (nonhealth) costs, mainly productivity losses and costs of informal care, which in the case of RA is important, given the disabling nature of the disease.

Another issue that should be taken into account when interpreting the results of the present analysis lies within an inherent problem of economic evaluations, that is, the transferability of cost-effectiveness data among varying healthcare settings. Although guidelines on the best practices for economic evaluation and the uniformity of calculations do exist, variability in the organization, administration of care, and, thus, costs, between health systems, renders the caution on the interpretation of the results a necessity.

Other important limitations that specifically apply to this study are the exclusion of research presented in languages other than English and the lack of full paper articles for some of the research presented. Specifically, for the majority of the ISPOR studies, only abstracts were retrievable. So, there remains a (small) degree of uncertainty as to whether all the information available internationally regarding the value of abatacept has been in fact included in the present 
review and therefore, the findings have to be treated with caution. Future similar reviews will be able to identify fulltext availability of the included research in abstract format. Finally, it has to be noted that one of the included studies [20] is a health technology assessment for the British National Institute for Health and Clinical Excellence (NICE), for which a small number of included studies may have been used in the analysis. The authors decided to include this HTA review, irrespective of this minor duplication, due to the significance of such a study. The review by Liu et al. [40] does not include any studies that have been identified and included in this analysis.

Rheumatoid arthritis is a disease with high prevalence and a significant social burden. Interventions with proven efficacy, such as abatacept, are an important addition to the clinician's armament. However, fiscal realities and scarce resources make cost-effectiveness data essential for decisions about treatment in the micro- (patient) as well as the macro(healthcare system) level. The majority of data from the international research shows that abatacept is both clinically efficient and highly cost effective in the treatment of moderate to severe rheumatoid arthritis, especially in patients that have demonstrated inadequate response or intolerance to antiTNF agents or DMARDs.

\section{Abbreviations}

$\begin{array}{ll}\text { ABA: } & \text { Abatacept } \\ \text { ADA: } & \text { Adalimumab } \\ \text { ANA: } & \text { Anakinra } \\ \text { CER: } & \text { Certolizumab } \\ \text { CRD: } & \text { Centre for reviews and dissemination } \\ \text { DARE: } & \text { Database of abstracts of reviews of effects } \\ \text { DMARDs: } & \text { Disease modifying antirheumatic drugs } \\ \text { ETA: } & \text { Etanercept } \\ \text { GOL: } & \text { Golimumab } \\ \text { HTA: } & \text { Health technology assessment } \\ \text { ICER: } & \text { Incremental cost-effectiveness ratio } \\ \text { INF: } & \text { Infliximab } \\ \text { IR: } & \text { Inadequate response } \\ \text { ISPOR: } & \text { International Society for Pharmacoeconomics } \\ & \text { and Outcomes Research } \\ \text { MTX: } & \text { Methotrexate } \\ \text { NHS EED: } & \text { National Health Service Economic Evaluation } \\ & \text { Database } \\ \text { NICE: } & \text { National Institute for Health and Clinical } \\ & \text { Excellence } \\ \text { NSAIDs: } & \text { Nonsteroidal anti-inflammatory drugs } \\ \text { TNF: } & \text { Tumour necrosis factor } \\ \text { RA: } & \text { Rheumatoid arthritis } \\ \text { RTX: } & \text { Rituximab } \\ \text { TOC: } & \text { Tocilizumab } \\ \text { QALY: } & \text { Quality adjusted life year. } \\ & \end{array}$

\section{Acknowledgments}

The present study was financially supported by BMS Hellas. The authors declare no conflict of interests.

\section{References}

[1] C. Lajas, L. Abasolo, B. Bellajdel et al., "Costs and predictors of costs in rheumatoid arthritis: A Prevalence-Based Study," Arthritis Care and Research, vol. 49, no. 1, pp. 64-70, 2003.

[2] E. Orlewska, I. Ancuta, B. Anic et al., "Access to biologic treatment in rheumatoid arthritis in central and Eastern European (EEC) countries," in Proceedings of the ISPOR 15th Annual International Meeting, 2010.

[3] J. Smolen, D. Aletaha, J. W. Bijslma et al., “Treating rheumatoid arthritis to target:recommendations of an international task force," Annals of the Rheumatic Diseases, vol. 69, pp. 631-637, 2010.

[4] "Summary of product characteristics for Orencia (BMs)," 2012, http://www.medicines.org.uk.

[5] J. Von Kempis, J. Dudle, P. Hasler et al., "Use of abatacept in rheumatoid arthritis," Swiss Medical Weekly, vol. 142, article w13581, 2012.

[6] "National Institute for Health and Clinical Excellence," 2012, http://www.nice.org.uk/.

[7] P. Kiely, C. Deighton, J. Dixey et al., "Biologic agents for rheumatoid arthritis-negotiating NICE technology appraisals," Rheumatology, vol. 51, pp. 24-31, 2012.

[8] A. Russell, A. Beresniak, L. Bessette et al., "Cost-effectiveness modeling of abatacept versus other biologic agents in DMARDS and anti-TNF inadequate responders for the management of moderate to severe rheumatoid arthritis," Clinical Rheumatology, vol. 28, no. 4, pp. 403-412, 2009.

[9] http://www.york.ac.uk/inst/crd/SysRev/!SSL!/WebHelp/5_5_ QUALITY_ASSESSMENT.htm, 2012.

[10] M. Vera-Llonch, E. Massarotti, F. Wolfe et al., "Cost-effectiveness of abatacept in patients with moderately to severely active rheumatoid arthritis and inadequate response to methotrexate," Rheumatology, vol. 47, no. 4, pp. 535-541, 2008.

[11] M. R. Alves, F. Carvalho Jr., and G. Litalien, "Cost effectiveness of abatacept in patients with moderately to severely active rheumatoid arthritis and indaquate response to methotrexate in Brazil," in Proceedings of the ISPOR 13th Annual International Meeting, 2008.

[12] R. Alfonso-Cristancho, E. C. Aiello, C. N. Roa et al., "What is the value of the new kid on the block? Tocilizumab versus abatacept in rheumatoid arthritis in Colombia," in Proceedings of the ISPOR 3rd Latin America Conference, 2009.

[13] R. Alfonso-Cristancho, N. Serra, E. C. Aielio, and C. N. Roa, "Abatacept or infliximab for rheumatoid arthritis in Venezuela? A cost-effectiveness analysis," in Proceedings of the ISPOR 16th Annual International Meeting, 2011.

[14] F. Becerra Rojas, C. Benites, E. C. Aiello et al., "Cost effectiveness of abatacept in comparison with other biologic therapies for the treatment of moderate to severe rheumatoid arthritis patients who have failed to methotraxate based treatment at Essalud in 2010," in Proceedings of the ISPOR 16th Annual International Meeting, 2011.

[15] R. Alfonso-Cristancho and E. C. Aiello, "Cost-effectiveness of abatacept versus infliximab for rheumatoid arthritis in Colombia," in Proceedings of the ISPOR 16th Annual International Meeting, 2011.

[16] M. Lebmeier, L. Pericleous, P. Drost et al., "The cost effectiveness of abatacept in combination with methotrexate for the treatment of patient with active rheumatoid arthritis after an inadequate response to methotrexate in the United Kingdom," 
in Proceedings of the ISPOR 13th Annual European congress, 2010.

[17] D. Zou, O. Desjardins, N. Tsao, and R. Goeree, "Canadian cost-effectiveness of abatacept (Orencia) for the management of moderate to severe rheumatoid arthritis in patients with inadequate response to methotrexate," in Proceedings of the ISPOR 15th Annual International Meeting, 2010.

[18] M. Benucci, W. Stam, I. Gilloteau et al., "Abatacept or infliximab for patients with rheumatoid arthritis and inadequate response to methotrexate: A trial-based and real-life cost-consequence analysis," in Proceedings of the ISPOR 14th Annual European Congress, 2011.

[19] K. Puolakka, H. Blafield, M. Kaupi et al., "Cost effectiveness modeling of sequential biologic strategies for the treatment of moderate to severe rheumatoid arthritis in Finland," The Open Rheumatology Journal, vol. 6, pp. 38-43, 2012.

[20] K. Malottki, P. Barton, A. Tsourapas et al., "Adalimumab, etanercept, infiximab, rituximab and abatacept for the treatment of rheumatoid arthritis after the failure of a tumour necrosis factor inhibitor: a systematic review and economic evaluation," Health Technology Assessment, vol. 15, no. 14, pp. 1-300, 2011.

[21] M. A. Cimmino, G. Leardini, F. Salaffi et al., "Assessing the cost-effectiveness of biologic agents for the management of moderate-to-severe rheumatoid arthritis in anti-TNF inadequate responders in Italy: a modeling approach," Clinical and Experimental Rheumatology, vol. 29, no. 4, pp. 633-641, 2011.

[22] T. A. Hallinen, E. J. Soini, K. Eklund, and K. Puolakka, "Costutility of different treatment strategies after the failure of tumour necrosis factor inhibitor in rheumatoid arthritis in the Finnish setting," Rheumatology, vol. 49, no. 4, pp. 767-777, 2010.

[23] A. Beresniak, R. Ariza-Ariza, J. F. Garcia-Llorente et al., "Modeling cost-effectiveness of biologic treatments based on disease activity scores for the management of rheumatoid arthritis in Spain," International Journal of Inflammation, vol. 2011, Article ID 727634, 9 pages, 2011.

[24] L. Pericleous and M. Lebmeier, "Cost-effectiveness of abatacept for the treatment of rheumatoid arthritis (RA) after the failure of a first TNF inhibitor in the United Kingdom," in Proceedings of the ISPOR 14th Annual European Congress, 2011.

[25] A. Saraux, L. Gossec, P. Goupille et al., "Cost-effectiveness modelling of biological treatment sequences in moderate to severe rheumatoid arthritis in France.," Rheumatology, vol. 49, no. 4, pp. 733-740, 2010.

[26] M. Vera-Llonch, E. Massarotti, F. Wolfe et al., "Costeffectiveness of abatacept in patients with moderately to severely active rheumatoid arthritis and inadequate response to tumor necrosis factor- $\alpha$ antagonists," Journal of Rheumatology, vol. 35, no. 9, pp. 1745-1753, 2008.

[27] Y. Yuan, M. Maier-Moldovan, R. M. Maclean et al., “The cost effectiveness of abatacept versus rituximab in patients with rheumatoid arthritis: a perspective of the Canadian publicly funded health care system," in Proceedings of the ISPOR 13th Annual International Meeting, 2008.

[28] M. G. Saggia, E. A. Santos, and V. Nasciben, "Cost minimization and budget impact analysis of rituximab versus infliximab, adalimumab, etanercept and abatacept from a payer perspective in Brazil," in Proceedings of the ISPOR 13th Annual International Meeting, 2008.

[29] S. Iannazzo, G. Giulani, O. Zaniolo et al., "New strategies in the treatment of rheumatoid arthritis in Italy: a budget impact analysis," in Proceedings of the ISPOR 11th Annual European Congress, 2008.
[30] L. Gossec, P. Goupille, A. Saraux et al., "Cost effectiveness simulation model of abatacept versus rituximab in rheumatoid arthritis in France," in Proceedings of the ISPOR 11th Annual European Congress, 2008.

[31] L. G. Mantovani, S. De Portu, M. Intorcia et al., "Cost utility of abatacept in rheumatoid arthritis patients with an insufficient response or intolerance to anti -TNF therapy in Italy: a Probabilistic sensitivity analysis," in Proceedings of the ISPOR 11th Annual European Congress, 2008.

[32] V. Brodzsky, F. Borgström, S. Arnetorp et al., "A costeffectiveness assemssment of abatacept for the treatment of rheumatoid arthritis in Hungary," Value in Health, vol. 11, no. 6, 2008.

[33] S. Ogale and H. J. Henk, "Rheumatoid arthritis (RA) treatment costs among U.S. patients treated with infused biologics," in Proceedings of the ISPOR 15th Annual International Meeting, 2010.

[34] P. Emery, P. Taylor, J. D. Isaacs et al., "Cost-effectiveness of biologic therapeutic sequence for rheumatoid arthritis in the UK," in Proceedings of the ISPOR 12th Annual European Congress, 2009.

[35] A. Beresniak, C. Baerwald, H. Zeidler et al., "Cost effectiveness simulation model of biologic strategies for the treatment of moderate to severe rheumatoid arthritis based on disease activity in Germany," in Proceedings of the ISPOR 12th Annual European Congress, 2009.

[36] A. Beresniak, V. Hamuryudan, M. Inanc et al., "Sequential cost -effectiveness modeling of different biologic strategies in rheumatoid arthritis in Turkey," in Proceedings of the ISPOR 12th Annual European Congress, 2009.

[37] S. Yunger, "An exploratory evaluation of the cost - effectiveness of rituximab and abatacept in the treatment of moderate to severe rheumatoid arthritisafter an inadequate response to a tumor necrosis factor in Canada," in Proceedings of the ISPOR 14th Annual International Meeting, 2009.

[38] G. Lewis, A. Kielhorn, and A. Diamantopoulos, "Costeffectiveness of rituximab (Mabthera) and abatacept (Orencia) for the treatment of moderate to severe rheumatoid arthritis (RA) in the UK," in Proceedings of the ISPOR 10th Annual European Congress, 2007.

[39] N. S. Minda Hawkins, D. Parry et al., "Cost-utility of abatacept, a new biologic therapy for patients with rheumatoid arthritis who failed anti-TNF therapy," in Proceedings of the ISPOR 10th Annual European Congress, 2007.

[40] Y. Liu, E. Q. Wu, A. G. Bensimon et al., "Cost per responder associated with biologic therapies for Crohn's disease, psoriasis, and rheumatoid arthritis," Advances in Therapy, vol. 29, no. 7, pp. 620-634, 2012.

[41] B. J. Wong, M. A. Cifaldi, S. Roy, D. C. Skonieczny, and S. Stavrakas, "Analysis of drug and administrative costs allowed by U.S. Private and public third-party payers for 3 intravenous biologic agents for rheumatoid arthritis," Journal of Managed Care Pharmacy, vol. 17, no. 4, pp. 313-320, 2011.

[42] Y. Yuan, D. Trivedi, R. MacLean, and L. Rosenblatt, "Indirect cost-effectiveness analyses of abatacept and rituximab in patients with moderate-to-severe rheumatoid arthritis in the United States," Journal of Medical Economics, vol. 13, no. 1, pp. 33-41, 2010.

[43] J. C. Cole, T. Li, P. Lin, R. Maclean, and G. V. Wallenstein, "Treatment impact on estimated medical expenditure and job loss likelihood in rheumatoid arthritis: e-examining quality of life outcomes from a randomized placebo-controlled clinical 
trial with abatacept," Rheumatology, vol. 47, no. 7, pp.1044-1050, 2008.

[44] W. N. Burton, A. Morrison, Y. Yuan, T. Li, R. E. Marioni, and R. Maclean, "Productivity cost model of the treatment of rheumatoid arthritis with abatacept," Journal of Medical Economics, vol. 11, no. 1, pp. 3-21, 2008.

[45] M. Maier-Moldovan, Y. Yuan, R. M. Maclean et al., "Cost effectiveness of abatacept in patients with rheumatoid arthritis (RA) and inadequate response to methotrexate (MTX) or tumour necrosis factor-alpha inhibitors (anti-TNFs): a Canadian perspective," in Proceedings of the ISPOR 13th Annual International Meeting, 2008.

[46] S. Iannazzo, G. Didoni, and D. Grocchiolo, "A budget impact for the use of abatacept as a first biologic treatment for rheumatoid arthritis in Italy," in Proceedings of the ISPOR 14th Annual European congress, 2011.

[47] M. G. Saggia and E. A. Santos, "Budget impact analysis of tocilizumab under the private payer perspective in Brazil," in Proceedings of the ISPOR 12th Annual European Conference, 2009.

[48] M. G. Saggia and E. A. Santos, "Budget impact analysis of tocilizumab under the public payer perspective in Brazil," in Proceedings of the ISPOR 12th Annual European Conference, 2009.

[49] M. R. Alves, F. Carvalho Jr., and G. Litalien, "Budget impact analysis of abatacept inclusion for moderate to severe rheumatoid arthritis in the Brazilian public system," in Proceedings of the ISPOR 13th Annual International Meeting, 2008.

[50] D. N. Trivedi, C. Kreilick, and L. C. Rosenblatt, "Real world costs and dosing patterns of abatacept and infliximab for the treatment of rheumatoid arthritis," in Proceedings of the ISPOR 13th Annual International Meeting, 2008.

[51] J. S. Smolen, R. Landewé, and F. C. Breedveld, "EULAR recommendations for the management of rheumatoid arthritis with synthetic and biological disease-modifying antirheumatic drugs," Annals of the Rheumatic Diseases, vol. 69, pp. 964-975, 2010 . 


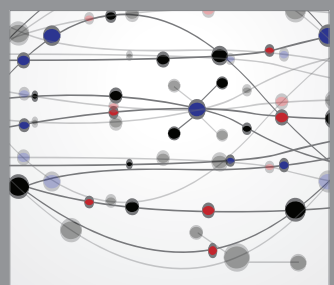

The Scientific World Journal
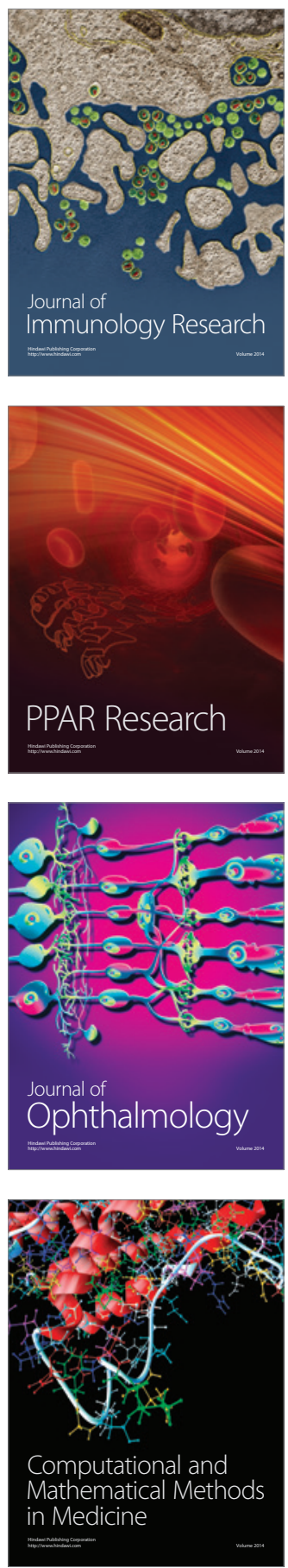

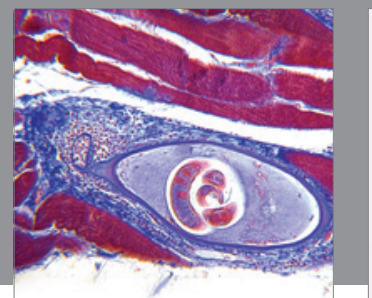

Gastroenterology

Research and Practice
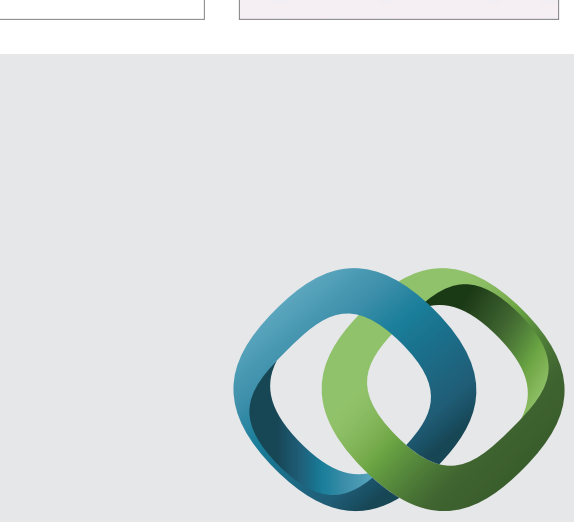

\section{Hindawi}

Submit your manuscripts at

http://www.hindawi.com
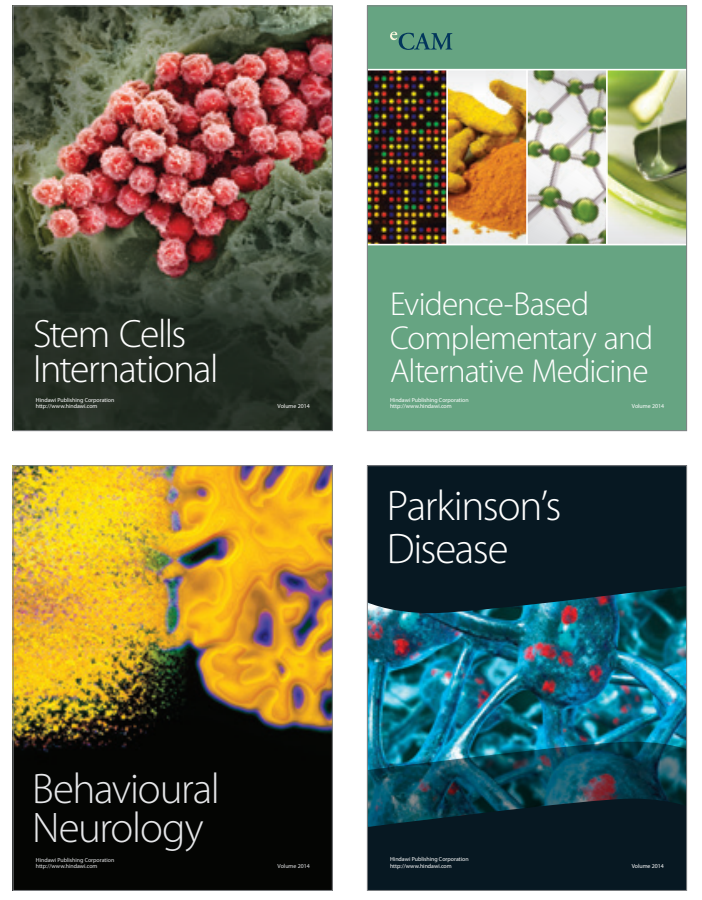
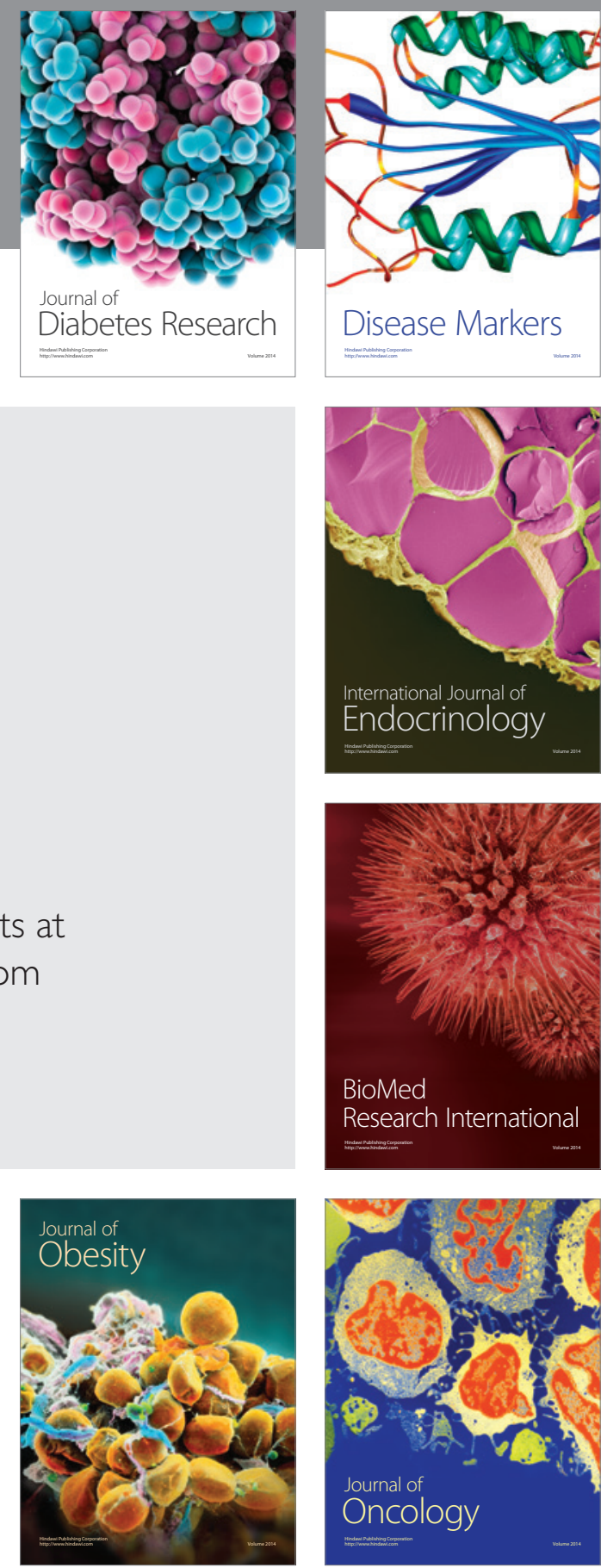

Disease Markers
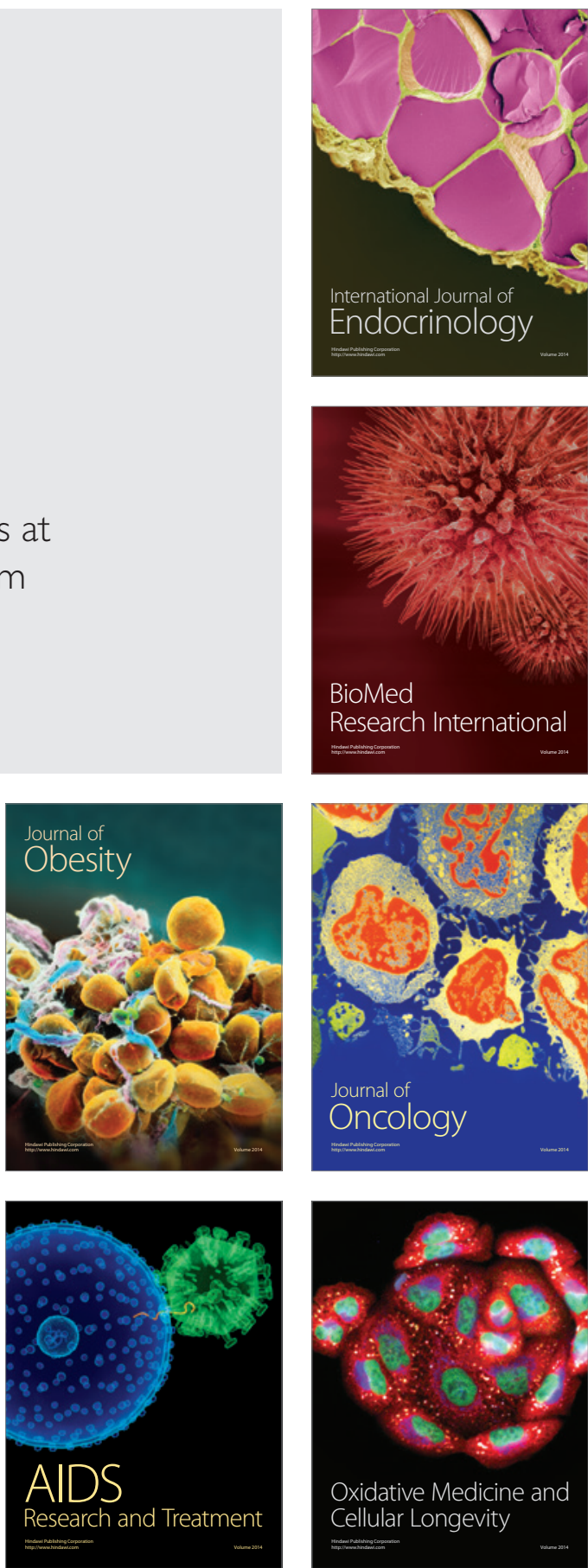